\title{
Orden, verdad, belleza: la poética del Mac-Mahon
}

\author{
Order, Truth, Beauty: The Poetics of Mac-Mahon
}

\author{
David Oubiña \\ Universidad de Buenos Aires / Conicet, Argentina \\ doubinia@retina.ar
}

\begin{abstract}
Resumen:
A comienzos de los años sesenta, el grupo de cinéfilos del Mac-Mahon se acercó a Cahiers du cinéma: durante un corto período de tiempo fueron cobijados por Éric Rohmer y su influencia en la revista creció rápidamente. Los macmahonianos propugnaron una puesta en escena transparente, un culto de ciertos actores viriles, un elogio de la violencia y, en general, un tono de escritura categórico, intolerante, dogmático, fuertemente confrontativo. Sus posturas extremistas generaron malestar entre algunos de los redactores de Cahiers du cinéma y el grupo acabó mudándose a la revista Présence du cinéma que, desde entonces, se convirtió en la tribuna de la doctrina macmahoniana. Este artículo estudia las implicancias de esta poética absolutista a la que Daney calificó como un "bazinismo de derecha" y que intentó recuperar los postulados aristotélicos en un momento en que el cine moderno pretendía poner en práctica las ideas de Brecht.
\end{abstract}

\begin{abstract}
:
In the early sixties, the cinephiles of the Mac-Mahon aproached the journal Cahiers $d u$ cinéma: during a short period of time, they were protected by Éric Rohmer and their influence on the journal grew quickly. The macmahonians advocated for a transparent mise en scène, a cult of certain virile actors, an eulogy of violence and, in general, a categorical, intolerant and dogmatic tone of writing, with a strongly belligerent attitude. Their perspective created a discontent among some of the established critics of Cahiers du cinéma and the group ended up moving to the journal Présence du cinéma that, since then, became the propagandist organ of the macmahonian doctrine. This article studies the implications of this absolutist poetics (defined by Daney as a "right wing bazinism") which tried to rehabilitate Aristotelian assumptions in the precise moment when modern cinema was more inclined to put into practice Brecht ideas.
\end{abstract}

Palabras clave: Mac-Mahon; Michel Mourlet; Cahiers du cinéma; Présence du cinéma; cine moderno.

Keywords: Mac-Mahon; Michel Mourlet; Cahiers du cinéma; Présence du cinéma; Modern Cinema. 


\section{Introducción}

En marzo de 1959, Luc Moullet escribe en Cahiers du cinéma: "los jóvenes cineastas norteamericanos no tienen nada para decir, y Sam Fuller menos que nadie" (p. 11). ${ }^{1}$ Aunque suene extraño, se trata de un elogio. Porque este desprecio por el tema no implica, en principio, una celebración de las formas vacías y tampoco supone un desinterés por aquello que el film dice; se trata más bien de trasladar completamente el sentido hacia la puesta en escena y destacar esa dimensión no como un mero vehículo sino como el núcleo duro de las películas. Y así como a Moullet no le preocupan las ideas de Fuller, sin ninguna culpa Fereydoun Hoveyda afirma que el argumento de Chicago, año 30 (Party Girl, Nicholas Ray, 1958) es banal, pero no considera que eso tenga ninguna relevancia para evaluar los méritos del film: "El tema de Party Girl es idiota. ¿Y qué?” (1960, p. 13) En realidad, no hay buenas y malas historias. Según los nuevos críticos de Cahiers, los directores mediocres tienden a refugiarse en los grandes temas como una estrategia para disimular su incapacidad. Lo que distingue a los autores geniales, en cambio, es "su habilidad para metamorfosear el argumento más estúpido a través de la técnica” (Hoveyda, 1960, p. 13).

A comienzos de la década del sesenta, los "jóvenes turcos” (Claude Chabrol, Jacques Rivette, François Truffaut, Jean-Luc Godard) están dedicados a sus propias películas y visitan cada vez menos la redacción de Cahiers $d u$ cinéma. Luego de la muerte de André Bazin, Éric Rohmer se ha hecho cargo de llevar la revista adelante acompañado por una nueva generación de redactores como Moullet o Hoveyda. Jim Hillier denomina a este período de la revista "la apoteosis de la mise en scène" (1986, p. 116). Es que, según estos nuevos críticos, los buenos films no están hechos para ilustrar un argumento previo. Tal como afirma Hoveyda, una película como Chicago, año 30

llega en el momento preciso para recordarnos que lo que constituye la esencia del cine no es otra cosa que la mise en scène. Es la puesta en escena

\footnotetext{
${ }^{1}$ En todos los casos, cuando las citas provienen de la versión original de un texto, la traducción me pertenece.
} 
lo que da expresión a todo lo que se representa sobre la pantalla y, como por arte de magia, transforma un guión escrito por otro e impuesto al director en un film de autor (1960, p. 14).

Es cierto que, todavía, autor y puesta en escena se mantienen ligados. Allí radica la singularidad de un estilo intransferible; pero, aun así, la relación entre los dos términos se va modificando paulatinamente. Cuando los jóvenes turcos entrevistaban a Renoir o a Rossellini o a Hitchcock, eso los autorizaba a ser considerados como sus discípulos. Se trataba de un diálogo entre un cineasta experimentado y un aspirante a cineasta; había, por lo tanto, una transmisión de un saber, un legado, una enseñanza. Los críticos de la nueva generación son más bien apóstoles de un estilo. Para ellos, Fuller o Walsh son primero el nombre sin rostro de una obra y luego, si llegan a entablar una relación personal, proyectan los valores estéticos sobre la figura del director (que ya no es una persona biográfica sino una criatura casi mítica). Moullet defiende tan encarnizadamente a Fuller que, cuando el realizador lee sus artículos, decide suscribirse a Cahiers du cinéma.

Se podría decir, entonces, que la política de los autores ha derivado en un culto de los autores, donde la lealtad facciosa ha sido reemplazada por el fetichismo de la liturgia. Para la nueva generación de críticos, los directores importan, por supuesto; pero importa más valorar sus films, como quien atesora un incunable. De miembros de una logia de iniciados a peregrinos iluminados. De la cinemateca a los pequeños cines de repertorio. Del enciclopedismo al coleccionismo. Este culto fetichista por ciertos cineastas alcanza el paroxismo en los textos de Michel Mourlet y el grupo de los macmahonianos que se acercan a Cahiers du cinéma y que luego terminarán refugiándose en la revista Présence du cinéma: desde allí defienden una estética absolutista y dogmática basada en la fascinación de la puesta en escena.

Este artículo analiza la propuesta de una restauración aristotélica por parte del grupo del Mac-Mahon, en un momento donde el cine moderno, en cambio, intentaba recuperar los postulados cuestionadores de Bertolt Brecht. 


\section{Misticismo de la puesta en escena}

Desde Sight and Sound, Richard Roud cuestiona lo que denomina la critique des beautés: "Para Hoveyda, como para muchos críticos franceses, $\mathrm{x}$ número de imágenes bellas equivale a un gran film" (1960, p. 170). Pero, aunque la puesta en escena adquiere un carácter definitorio en la poética de un auteur, no se trata de una opción por la forma frente al contenido sino -en su aspecto más razonable- de la insistencia por leer los sentidos en la especificidad estilística de cada cineasta. Es cierto que para Hoveyda y para muchos de los nuevos críticos de Cahiers, esa noción de mise en scène adquiere una importancia excluyente; sin embargo, no tiene el mismo sentido para todos. Para Michel Mourlet, por ejemplo, la puesta en escena cinematográfica no es una técnica sino una energía misteriosa y por lo tanto inapresable. Dice en "Sur un art ignoré:

El arte ha sido siempre una puesta en escena del mundo, es decir una posibilidad ofrecida a la realidad contingente e inacabada de realizar los deseos del hombre. Pero ese mundo no podía ser captado sino por un intermediario, había que recrearlo mediante una materia indirecta, había que transponerlo, había que proceder por alusiones y convenciones porque era imposible una posesión inmediata (1959, p. 24).

Orden, verdad y belleza son las coordenadas que definen el arte de la mise en scène según Mourlet. A diferencia de las otras artes, el cine no inventa un lenguaje ni establece convenciones. Mientras que en aquellas la distorsión de la realidad es una necesidad expresiva (es su condición de posibilidad), en las imágenes objetivas del cine todo eso aparece inevitablemente como una mentira. En las películas no debe haber símbolo ni metáfora. No hay desvío posible. No se trata de una composición significante que debe ser decodificada sino de una experiencia sensible a la que el espectador se entrega por completo. ${ }^{2}$

2 Según Marc Cerisuelo: "Para un macmahoniano consecuente como Michel Mourlet, es
simplemente inconcebible amar, a la vez, a Preminger y a Hitchcock. El macmahonismo tuvo
su base común en la concepción aristotélica de la acción, regulada según una mimesis que no
se puede desarreglar. El espectador de cine debe ser capturado por el film, debe caer en un 
El artículo de Mourlet se imprime enteramente en itálica y va precedido por una nota aclaratoria donde la revista toma distancia de un texto que respeta pero que considera muy extremista. El cine moderno, que está surgiendo en ese momento, tiende a alejarse de los postulados bazinianos sobre la realidad revelada y, en cambio, se acerca a los preceptos brechtianos que ponen el acento sobre el funcionamiento del dispositivo cinematográfico. En ese contexto, el artículo de Mourlet es leído como el manifiesto de un pequeño grupo resistente a los embates de la modernidad y le valdrá a su autor el título de "el Boileau del Mac-Mahon”. Luego de la guerra, el cine Mac-Mahon se había especializado en la exhibición de films de Hollywood en versión original, destinados a los soldados estadounidenses que se hospedaban en los diversos hoteles de la zona, en las cercanías de Place de l'Etoile. Truffaut y Godard fueron asiduos espectadores a mediados de los 50; pero en seguida, una nueva generación de cinéfilos toma posesión del lugar y lo convierte en el templo sagrado para cultivar su fanatismo por el cine norteamericano. Michel Mourlet, Pierre Rissient, Jacques Serguine, Michel Fabre, Marc Bernard desarrollan una fervorosa idolatría por Joseph Losey, Otto Preminger, Fritz Lang y Raoul Walsh ("los cuatro ases", cuyos retratos podían verse sobre las paredes del hall del cine), aunque también por Allan Dwan, Sam Fuller, Jacques Tourner, Cecil B. de Mille y otros directores menos relevantes como Don Weis, Edward Ludwig o Vittorio Cottafavi. Esos cinéfilos de "Le Cercle du Mac-Mahon" son cobijados durante un tiempo entre las páginas de los Cahiers de Rohmer y Douchet (que, en varios aspectos, los sentían cercanos) y, durante un tiempo, ejercen notable influencia sobre el estilo de la revista. Si bien algunos de esos directores ya habían sido rescatados en los años cincuenta por la política de los autores, los macmahonianos desprecian a la Nouvelle vague y a muchos de los auteurs modernos preferidos por los Cahiers como Hitchcock, Welles, Visconti, Antonioni o Bergman.

Los macmahonianos constituyen una especie de secta: paladines de una estética de la provocación donde se mezclan el heroísmo con la misoginia, la violencia, el sadismo, el erotismo y el racismo. Se especializan en encontrar estado de fascinación que los artificios del montaje no puedan perturbar” (2013, p. 25). 
películas raras o despreciadas o inéditas: lo que Antoine de Baecque llama el "chantaje de la obra maestra ignorada" como un desafío a la cinefilia tradicional (1991, p. 63). Más que un espacio físico, el Mac-Mahon es, ante todo "una idea de cine". Años después, Louis Skorecki señala que son los únicos cinéfilos que permanecieron fieles a su lógica hasta el fin y rescata su rigor conceptual:

Su teoría se resume en algunas frases: existe una perfección del cine a la cual ciertos films se aproximan, y es esa perfección lo que debemos perseguir sin cesar, una transparencia, una adecuación del estilo a la materia, una elegancia y una inteligencia del gesto, una economía de medios: teoría del momento privilegiado, es decir, el triunfo y la sublimación del fragmento, un fragmento que poseería tal belleza y tal fuerza de evidencia que constituiría por sí solo un modelo, el modelo al que todo el cine debería tender (1978, p. $33)^{3}$.

Todo el razonamiento de Mourlet en "Sur un arte ignoré" hace equilibrio, de manera elegante, sobre una lógica de contradicciones que podría hacerlo naufragar pero que es, justamente, lo que le confiere potencia. Jacques Aumont señala aquí una deliberada inestabilidad entre postulaciones modernas y clásicas:

Moderno es, en Mourlet, el recurso a la idea de genio creador que substituye a la idea de una comunidad artística que establece reglas y se beneficia de los progresos comunes (...) Pero contradictoriamente, dicho artista cree aún que es posible situar en el corazón de la empresa artística el problema de la verdad (y por lo tanto, del error o la falsedad). En resumen, el artista crea, al grado de su 'voluntad' creadora, pero no podría crear cualquier cosa: él 'recrea el mundo'. si románticamente es un vidente, somete clásicamente su visión a la obligación de compartirla con completa claridad (2010, pp. 7677).

En el cine el mundo no es simbolizado, sino que se hace presente sin mediaciones. Se da a ver, es capturado por la cámara y revelado en su verdad a través de la puesta en escena. Eso que sale a la luz ya estaba ahí; pero no es

3 Véase, también, la respuesta de Pascal Kané (1978) donde acusa a Skorecki de "terrorismo cinefílico" y niega que los macmahonianos hayan constituido una escuela de crítica. 
sólo que ha salido al encuentro de la cámara, sino que ella lo ha elevado a una forma superior. Mourlet parte de las ideas de Bazin (una especie de rohmerobazinismo), pero para construir sobre ellas una teoría de lo espectacular. En esa configuración ideal (esos raros instantes que sólo pueden ofrecernos los más grandes directores), el cine logra que el espectador anule toda distancia y se deje atrapar por una fascinación hipnótica frente a lo representado en la pantalla. El realismo en bruto le repele a Mourlet tanto como la pura imaginación. La esencia del cine no está en la apariencia documental ni en el artificio de hechicería; en todo caso, es documental y hechicería a la vez. El mundo está ahí, pero como una presencia ideal, cercano y distante. Más que una revelación, se trata de un deslumbramiento. Mourlet parte de una fenomenología a la manera de Bazin, pero se aleja de ella hacia un antihumanismo de tono nietzscheano que acaba inmerso en una contemplación litúrgica. Ver un film es, entonces, una experiencia aurática que se asemeja el éxtasis religioso. Un bazinismo no baziniano, se podría decir.

Hoveyda admite que tanto él como los macmahonianos postulan la preeminencia de la mise en scène pero afirma que sus diferentes enfoques conducen a resultados opuestos e irreconciliables. Mourlet critica la perspectiva metafísica de muchos de los artículos de Cahiers pero, según Hoveyda, no hace más que reemplazarla por su propia metafísica. En efecto, eso es lo que escribe sobre Losey: "Es el único cineasta cósmico. Representa la realización plena del proyecto cinematográfico ya que le devuelve al mundo su brutalidad originaria" (Mourlet, 196ob, p. 35). El problema con Mourlet es que su teoría abstracta de la fascinación que ejerce la puesta en escena sobre los espectadores lo exime de explicar nada mediante ejemplos concretos. ¿Cuál es el motivo por el que se debería preferir Amazonas negras (The Adventures of Haji Baba, Don Weis, 1954) a Noches blancas (Le notti bianche, Lucchino Visconti, 1957), o Il Boia de Lilla. La vita avventurosa de Milady (Vittorio Cottafavi, 1952) a Te querré siempre (Viaggio in Italia, Roberto Rossellini, 1954)? La obra está hecha de signos, pero no de significados. Igual que Barthes, Hoveyda piensa la técnica en términos de significación allí donde Mourlet se entrega a la fascinación mística. Y como el éxtasis místico siempre se cruza con el éxtasis erótico, el objetivo último de la 
puesta en escena es, para los macmahonianos, un himno a la gloria del cuerpo. El centro de ese mundo ideal impuesto por el cine está ocupado por algunos pocos actores esenciales. Pero no se trata, por supuesto, de actuar en el sentido convencional del término: esos actores esenciales son los que están dotados de una mirada, una voz y una gestualidad singulares y, por lo tanto, el arte de los grandes cineastas consiste en provocar esa naturaleza para extraer de ella toda la potencia de la que es capaz. Esa potencia es, siempre, pre-potencia: porque la seducción supone lo belicoso y lo brutal.

\section{Elogio de la violencia}

En un texto tan célebre como polémico, Mourlet dice que el cine es el arte que mejor sintoniza con la violencia. Mientras que las otras artes sólo pueden sugerir ese torrente desbocado, el cine puede observarlo en toda su plenitud. La violencia es aquí la fuente de una belleza a la que se arriba mediante el drama de los cuerpos. Fascinación de los macmahonianos por ciertos actores (por los cuerpos de ciertos actores) cuya sola presencia es el vehículo más directo para alcanzar una armonía del mundo "que es a la vez más real y más elevada”. Esa fascinación llevaría a promover el extraño e inexplicable culto a Charlton Heston. Sobre él, Mourlet escribe:

Charlton Heston es un axioma. Constituye una tragedia en sí mismo y su presencia en cualquier film - no importa cuál- es suficiente para convocar a la belleza. La violencia contenida expresada por la sombría fosforescencia de sus ojos, su perfil aguileño, el orgulloso arco de sus cejas, sus prominentes pómulos, la amarga y dura curva de su boca, el fabuloso poder de su torso: esto es lo que le ha sido dado y lo que ni el peor director podría degradar (1960, pp. 24-25).

Charlton Heston encarna la esencia del cine -declara Mourlet- mucho más que Ciudadano Kane (Citizen Kane, Orson Welles, 1941) o Hiroshima mon amour (Alain Resnais, 1959). En realidad, el corpus heroicus de los macmahonianos está encabezado por Heston, pero se amplía para incluir otros nombres, bellos y fuertes, como Fernando Lamas, Robert Wagner o Jack Palance (aunque, en este caso, se trata de una "espléndida fealdad 
salvaje”). Un director debe ser fiel a ciertos intérpretes, así como un escritor tiene predilección por ciertas figuras de lenguaje o un pintor por cierta paleta de colores. Eso es lo que sucede con Preminger y sus actrices: Jean Simmons, Gene Tierney, Kim Novak, Jean Seberg. Un ejemplo inverso le permite a Mourlet explicarse por la negativa: "Fellini se ha casado con Giulietta Masina, por lo tanto sus films son grotescos. Eso es lo que había que demostrar" (1959, p. 35).

De la política de los autores a la política de los actores. Si en los textos de Hoveyda puede advertirse una transformación que surge de revisar los viejos postulados de la revista, pero manteniendo cierta continuidad con ellos, en los axiomas de los macmahonianos, en cambio, parecería que las viejas fórmulas de la revista han sido puestas a girar en una órbita alucinada. El macmahonismo es una política de los autores enloquecida, siempre al borde de un fanatismo paródico, como si Charlton Heston obligara a los jóvenes turcos a confrontarse con el punto ciego de sus apotegmas. Los Cahiers $d u$ cinéma se encuentran, de pronto, con la horma de su propio zapato. Rivette se queja:

No es sólo cuestión de hablar sobre la fascinación de la imagen que se ve sobre la pantalla, sino que se trata de entender cómo la mise en scéne es la expresión de la inteligencia del director (...) Cuando nosotros defendíamos a Preminger, o a Hawks, o a Hitchcock, debería haber sido evidente que era su visión personal del mundo lo que queríamos acercar a los espectadores. Pero toda esa idea ha sido distorsionada hasta el punto de la imbecilidad y, entonces, ahora se usa para sugerir que, en la medida en que un movimiento de cámara puede ser sublime, no hay diferencia si la historia es fatua, el diálogo idiota y la actuación atroz. Esto, me parece, es exactamente lo opuesto de todo aquello por lo que nosotros combatimos bajo el estandarte de la mise en scène, cuando insistíamos en la importancia de establecer qué era la autoría de un film (Marcorelles, 1963, p. 170).

Los reclamos suenan razonables, ¿̇pero acaso no es posible entender el elogio de la violencia según Mourlet como una evolución (o involución) de los argumentos del propio Rivette en "Notes sur une revolution"? Mourlet sitúa a Elia Kazan en el escalón más bajo de su escala virtuosa de la violencia: la 
suya es una violencia falsa, pueril y gratuita cuya expresión más acabada es el “despreciable Karl Malden”. En Welles, la violencia resulta más honesta, pero no logra escapar al berrinche de "un niño pateando los muebles cuando se golpea contra ellos”. La de Buñuel es una violencia apasionada pero todavía ligada al sentimiento adolescente (ése que todo espectador experimenta al descubrir el cine). En Nicholas Ray hay una violencia más sensual, más real: “James Mason para siempre al borde de las lágrimas”. Pero recién con Walsh se puede advertir la verdadera belleza de la violencia: el deseo de triunfar, el coraje de vivir (es que el hombre está hecho para la guerra, dice Mourlet citando a Zarathustra). Y si en Walsh la violencia es a cielo abierto, en Lang es subterránea, asfixiante, contenida, aunque nunca arruinada por la debilidad como en Ray. No obstante, el cineasta que más profundamente se adentra en la violencia -más que Walsh o Lang- es Joseph Losey y por eso es el mejor de todos:

En Losey, la violencia está justo debajo de la piel y captura ese momento en que el pulso se acelera frenéticamente al tiempo que, con cada latido magnificado del corazón, un hombre se inclina para enfrentar lo que se cruza en su camino. Y en la medida en que lleva a cabo su objetivo, se descubre una cierta calma, una cierta detumescencia. Es la violencia que abre la puerta a la paz y que anuncia un desacostumbrado desborde de felicidad (1960, 27).

En septiembre de 1960, Cahiers du cinéma dedica un número a Losey y, por supuesto, su organización queda a cargo de los macmahonianos: entrevista de Fabre y Rissient con el realizador más una biofilmografía y textos de Serguine, Rissient, Bernard y Mourlet. El argumento que recorre los artículos es siempre el mismo. Tal como lo formula Jacques Serguine: "Descubrimos la regla fundamental: no debe existir sobre la pantalla nada que no pueda existir en el mundo de los hombres" (1960, p. 42). Frente a los cineastas que inventan formas, que producen "espejos deformantes", que poseen un universo estilístico, Losey opone la objetividad, la visión pura y transparente, la claridad de conciencia. Esa ausencia de estilo que le cuestionan sus detractores es, en cambio, su más alta cualidad. Losey no había sido hasta ese momento un autor Cahiers y, de hecho, su estilo (o su falta de estilo o su estilo oportunista que se adapta al tema de cada film) es la negación de la 
politique des auteurs tal como la habían planteado en su momento los jóvenes turcos. En todo caso, no porque impugne el concepto de autor sino porque discute sus fundamentos y desplaza su eje. Es posible que nadie haya profesado un culto tan fanático por ciertos nombres propios como estos "neo-jóvenes turcos"; pero la autoría ya no es una cuestión temática o estilística, precisamente porque los grandes cineastas son aquellos que eligen un modo de aproximación al mundo más bien frío, neutro y distante. Hay autores, por supuesto, pero esa selección es tan categórica como restrictiva. No son los que han construido un universo propio sino aquellos que logran ver el universo. Por eso, según Mourlet, analizar los films de Hitchcock a partir de un tema común (el desplazamiento de la culpa, por ejemplo) es como pretender hacer un comentario sobre La balsa de la Medusa y sobre Géricault apelando a las peripecias del naufragio y la edad del capitán. Lo único que importa es lo que vemos sobre la pantalla. Pero de este modo, llevando al extremo la actitud facciosa de los hitchcocko-hawksianos, los cinéfilos de Mac-Mahon (esos "glotones ópticos", tal como los denominó Pierre Kast) acaban desvirtuando los fundamentos de la politique des auteurs: porque ya no es una política sino una autocracia despótica ejercida alrededor de cuatro o cinco cineastas.

Para Serguine todo amante del cine es un macmahoniano aunque lo ignore. Por lo tanto,

No me parece importante preguntar: ¿cómo se puede ser macmahoniano? Lo que importa es buscar: ¿cómo se puede ser Raoul Walsh? ¿cómo se puede ser Fritz Lang y cómo Joseph Losey? Aún no lo se. Sé que existen y nada más. Lo bello es la evidencia de lo bello, ésa es la paradoja. El macmahonismo no es una respuesta fácil, demasiado fácil; es una pregunta exigente (1960, p. 45).

Como se ve, Serguine recupera la vieja pregunta a propósito de los Hitchcocko-Hawksianos para aplicarla a los nuevos cinéfilos, como si los macmahonianos vinieran a ocupar ese lugar de rebeldía que habían dejado vacante los jóvenes turcos. Pero, en realidad, Serguine parafrasea a Bazin para señalar que esa pregunta ya no tiene sentido: Mac-Mahon es el nombre de la cinefilia y cualquier amante del cine debería advertir que sólo vale la pena hablar de Walsh, de Losey o de Lang. Y de nadie más. Para usar la 
propia contabilidad de los macmahonianos: el $95 \%$ de eso que llamamos cine no tiene nada que ver con el cine. Y esos cineastas ("los cuatro ases" y unos pocos más) se constituyen como autores sólo en la medida en que encarnan una especie de fuerza mítica que los excede y que proviene, convenientemente, de un más allá sublime. Esa energía es, en cierta medida, involuntaria o inapelable. Una energía que circula a través de ellos, pero que no les pertenece. Pero entonces, habría que admitir que los auteurs propuestos por los macmahonianos son, paradójicamente, los menos autores porque permanecen al servicio de un sistema de producción donde la puesta en escena es sólo una parte del proceso creativo: "la cinefilia macmahoniana se funda, de hecho, sobre una fascinación por la máquina hollywoodense" y, en definitiva, esa elección excluye a aquellos cineastas que logran apropiarse $\mathrm{y}$ transformar esa maquinaria en su provecho puesto que los rasgos expresivos individuales terminarían por corromper la pureza de la puesta en escena.

\section{Conclusión}

El número especial Losey señala el punto más alto de la influencia macmahoniana en los Cahiers. Pero es, también, el final. Para Doniol Valcroze todo esto supone un giro hacia la derecha: evidentemente Rohmer y Douchet se han acercado demasiado a estos neo-jóvenes turcos (la propia lógica de sus argumentos los ha llevado hasta allí) y han dejado crecer su poder hasta un punto donde la situación amenaza con volverse incontrolable. Ya no es una admiración por los raros o los malditos de Hollywood sino una inquietante idolatría por cierto cine americano como arte superior que es correlativa de un desprecio no sólo hacia la Nouvelle vague sino hacia la mayoría de los realizadores modernos como Bergman, Buñuel o Antonioni.4

\footnotetext{
4 Douchet escribe, desde el Festival de Cannes 1962, que El ángel exterminador (Luis Buñuel, 1962) lo ha "aburrido profundamente" y, aunque sabe que el film será defendido por sus admiradores dentro de la revista, declara que "ni por todas las razones del mundo, incluso las más válidas, me dejaré convencer del talento de Buñuel" (Douchet y Moullet, 1962, p. 27). Su opinión sobre Antonioni es aún peor: "El eclipse podría ser el del autor. Todos los tics de Antonioni -iy Diós sabe que los tiene!- aparecen aquí con complacencia (...) No digo que sea un autor despreciable: digo que va hacia el error, error que, en $E l$ eclipse, deviene una monstruosidad" (p. 30).
} 
A partir de entonces, Mourlet y sus acólitos se retiran de la revista para refugiarse en Présence du cinéma, la publicación que habían fundado Jean Curtelin y Michel Parsy (los programadores de la sala Mac-Mahon) en 1959 y que ahora, a partir del número 9, se relanza como órgano oficial de los macmahonianos. En el "Avant-propos” para ese nuevo comienzo de Présence du cinéma, Curtelin escribe que ha decidido volver a editar la revista "por una razón muy simple: porque nos parece indispensable ofrecer una tribuna a Michel Mourlet y a sus amigos. Son la base y los elementos precursores de todo un cine por venir, tal como lo fueron en su momento François Truffaut y Jacques Rivette en la época de oro de los Cahiers du Cinéma” (1962, p. 1).5 El gesto es el mismo. Y la intensidad del discurso, también. Lourcelles define a Cecil B. De Mile con la misma certeza que Truffaut podría haber empleado para defender a Hitchock ("La obra de De Mille es la más coherente de la historia del cine”) y Mourlet escribe sobre Vittorio Cottafavi con las mismas fórmulas que Rivette podría haber aplicado a Howard Hawks: Le vergini di Roma (Las vírgenes de Roma, Vittorio Cottafavi, 1961) o Las legiones de Cleopatra (Le legioni de Cleopatra, Vittorio Cottafavi, 1959) son tragedias a la manera de Racine, realizadas por un director que en cada uno de sus films “inventa el cine" (Lourcelles, 1967, p. 1 y Mourlet, 1961, p. 31). Pero, aunque hay, ciertamente, una curva que conecta al gusto de los jóvenes turcos por la serie B y la fascinación de los nuevos cinéfilos por el peplum, el cine bizarro, los films épicos o el thriller delirante, hay una divergencia flagrante entre la elegancia de las formas puras que los hitchcocko-hawksianos rescataban en el cine clásico y la desmesura, la ferocidad y el exceso que los macmahonianos exaltan en ese "neo-irrealismo italiano" (tal como lo denomina Michel Mardore).

En el editorial del número 18, cuando se anuncia que la revista vuelve a tener una frecuencia mensual, Présence du cinéma ironiza porque a todas las revistas de cine les parece de buen tono hablar de "combate". ¿Pero luchar por qué y por quién? Para Présence du cinéma, la tarea a realizar se expresa en la palabra "vindicación" (que la revista escribe en castellano, aunque se olvida la tilde):

5 Sobre Présence du cinéma, véase Justine Alleron, 2018. 
Palabra ideal para caracterizar un estado de espíritu que no nos abandona. Palabra admirable a causa de todas las nociones que, derivadas del sentido primero (venganza), se reencuentran y se exaltan mutuamente: la justicia, la idea de restitución (devolver, a quien ha sido subestimado o ignorado o ridiculizado, lo que le corresponde), la premeditación, la frialdad, la violencia y el homenaje (Présence du cinéma, 1963, p. 1).

Hay furia y crispación en el tono: la sensación de que la historia del cine ha sido injusta con los grandes directores. Publicar una revista es una misión casi sagrada. Una guerra santa. Vindicar supone defender y atacar, reparar una ofensa, recuperar un territorio perdido: "Todo lo que es importante en el cine será siempre más macmahoniano que nosotros y nos precede" (Présence du cinéma, 1963, p. 2). Y como hay que concentrar esfuerzos, Présence du cinéma se dedica casi de manera monográfica a uno o dos cineastas por número: Otto Preminger, Don Weis, Raoul Walsh, Sam Fuller, Allan Dwan, Jacques Tourner, Riccardo Freda.

Cuando estamos en el extranjero -comenta Godard-, nos encontramos con gente que nos dice 'iRiccardo Freda, creen que es serio!' Ya nos costó lo nuestro hacer que fueran capaces de admitir que tipos como Nicholas Ray y Robert Aldrich tuvieran genio, ipero cuando leen en la revista entrevistas de gente como Ulmer, abandonan! Estoy a favor de la política de los autores, pero no de cualquiera, me parece que querer abrir la puerta a todo el mundo es una cosa muy peligrosa. Porque entonces la inflación se convierte en una amenaza (Collet, J. et al, 1962, p. 130) ${ }^{6}$.

Igual que Rivette, Godard se lamenta porque la política de los autores se ha aplicado de manera indiscriminada, de modo tal que cualquier metteur en scène pasa a la categoría de auteur cuando, en realidad, para los jóvenes turcos se trataba justamente de excepciones. En todo caso, los verdaderos artistas carecen de vanidad o petulancia: Renoir y Ophuls eran artistas casi a pesar suyo. Intentaban llevar a cabo su oficio de manera eficiente, pero tenían genio y eso introducía una diferencia categorial. Mientras que ahora se

${ }^{6}$ No casualmente, en ese mismo momento Présence du cinéma prepara un número monográfico sobre Freda a cargo de Jacques Lourcelles. Véase Présence du cinéma $\mathrm{n}^{0}{ }_{17}$, primavera de 1963. 
trata de meros especialistas o técnicos que algunos consideran artistas como si eso les diera alcurnia o como si hubieran comprado un título de nobleza.

En el film Les sièges de l'Alcazar (1989), Moullet narra el accidentado romance entre un crítico de Cahiers du cinéma -que bien podría ser el propio Moullet- y una crítica enemiga de la revista Positif.7 Como entre los Montescos y los Capuletos, todo se opone a esa relación: ella ama a Antonioni y él lo odia, ella desprecia a Cottafavi y él lo idolatra. Todo transcurre entre las butacas del cine Alcázar -que bien podría ser el cine Mac-Mahon-, en la oscuridad y a escondidas, porque él teme que algún colega de Cahiers lo vea con ella. Un día el afiche de promoción en la puerta del cine ostenta un error: L’Affranchi es adjudicada a Ottavio Scotti. El crítico, convencido de que se trataba de una película de Cottafavi, entra en crisis: “¿Y si L’Affranchi no era un film de Cottafavi? ¿Acaso no amaba yo ese film justamente porque era de Cottafavi? ¿O entonces Ottavio Scotti era un genio?” He ahí, en forma paródica, toda la política de los autores en versión macmahoniana. Llevada al extremo, toda teoría se vuelve un poco absurda. Mourlet escribe: "La poesía crea su materia. En cambio, puesto que la materia le es dada al cine, la belleza no será reconstruida por el cineasta sino discernida, identificada por el objetivo (...) El poeta es el poeta del lenguaje, pero el cineasta es el poeta de lo real" (1961, p. 94). Hay algo baziniano en esta valoración de un cine que conoce el mundo a través de la cámara; pero también hay algo completamente anti baziniano, porque supone una cualidad casi neutral del artista. Daney dirá que el macmahonismo fue "una recaída dogmática, de extrema derecha, del bazinismo" (1983, p. 15). Al final de la película de Moullet, el protagonista reflexiona: "Estaba orgulloso de haber convencido a todo el mundo sobre el genio de Cottafavi. Pero también estaba triste: Cottafavi ya no me pertenecía sólo a mí. Su éxito me inquietaba: ¿eso quería decir que era un mal film?” Los textos de Mourlet son a menudo notables (aunque siempre discutibles). El problema, sin duda, no es ése sino que Présence du cinéma está obligada a avanzar inevitablemente hacia el fondo

\footnotetext{
7 En el título, las butacas (sieges) del cine Alcázar juegan con el nombre de una vieja película italiana pro-franquista: Sin novedad en el Alcázar (L'assedio dell'Alcazar, Augusto Genina, 1940; exhibida en Francia como Le siege de l'Alcazar) sobre el sitio al Alcázar de Toledo durante la Guerra Civil.
} 
de un callejón. No puede sino convertirse en una logia para iniciados, tan cerrada que, forzosamente, acaba rechazando todo lo nuevo. Y a en la década de 1960, lo nuevo es la Nouvelle vague y todos los cines modernos que surgen detrás de ella.

\section{Referencias bibliográficas}

Alleron, J. (2018). Singularités de la revue Présence du cinéma au sein du contexte critique des anées 1950 et 1960. Université de Rennes 2. En línea, 22 de abril de 2019. https://dumas.ccsd.cnrs.fr/dumas01835203

Aumont, J. (2010). El cine y la puesta en escena. Buenos Aires: Colihue.

Cerisuelo, M. (2013). Le Mac-Mahon : histoire et legende. En Creton, L. y Kitsopanidou, K. (Eds.), Les salles de cinéma. Enjeux, défies et perspectives (pp. 19-28). París: Armand Colin.

Collet, J., Delahaye, M, Fieschi, J., Labarthe, A. y Tavernier, B. (1962). Entrevista con Jean-Luc Godard. En VV.AA., La Nouvelle Vague: sus protagonistas (pp. 95-130). Barcelona: Paidós.

Curtelin, J. (1961). Avant-propos. Présence du cinéma $\mathrm{n}^{\circ}$ 9, 1-2.

de Baecque, A. (1991). Histoire d'une revue (Tome I : À l'assault du cinéma 1951-1959). París: Cahiers du cinéma.

Daney, S. (1983). La rampe. París: Cahiers du cinéma.

Douchet, J. y Moullet, L. (1962). Cannes 1962. Cahiers du cinéma no 132, 2235 .

Hillier, J. (1986). Cahiers du cinéma 196o-1968: New Wave, New Cinema, Reevaluating Hollywood. Cambridge: Harvard University Press.

Hoveyda, F. (1960a). La réponse de Nicholas Ray. Cahiers du cinéma n ${ }^{107,}$ 13-24.

Hoveyda, F. (1960b). Les taches du soleil. Cahiers du cinéma no 110, 33-43.

Kané, P. (1978). Réponse a «CNC». Cahiers du cinéma nº 293, 52-55.

Lourcelles, J. (1967). Avant propos. Présence du cinéma no 24/25, 1-2.

Marcorelles, L. (1963). Interview: Roger Leenhardt with Jacques Rivette. Sight and Sound, 4 (32), 168-173.

Moullet, L, (1959). Sam Fuller sur les brisées de Marlowe. Cahiers du cinéma $\mathrm{n}^{\mathrm{o}} 93,11-23$.

Mourlet, M. (1959). Sur un art ignoré. Cahiers du cinéma $\mathrm{n}^{0}$ 98, 23-38.

Mourlet, M. (1960a). Apologie de la violence. Cahiers du cinema $\mathrm{n}^{0}$ 107, 2428. 
Mourlet, M. (196ob). Beauté de la connaissance. Cahiers du cinema n ${ }^{0} 111$, 34-38.

Mourlet, M. (1961). Du côté de Racine. Présence du cinéma nº 9, 29-32.

Mourlet, M. (1965). Cinéma, poésie et autres. Sur un art ignoré (pp. 93-94). París: La table ronde.

Présence du cinéma. (1963). Éditorial. Présence du cinéma $\mathrm{n}^{0} 18$, 1-2.

Roud, R. (1960). The French Line. Sight and Sound 4 (29), 166-171.

Serguine, J. (1960). Éducation du spectateur ou l'École du Mac-Mahon. Cahiers du cinéma $\mathrm{n}^{0} 111,39-45$.

Skorecki, L. (1978). Contre la nouvelle cinéphilie. Cahiers du cinéma nº 293 , 31-51. 